\title{
AGROECOLOGIA, AGRICULTURA ORGÂNICA E INSTITUCIONALIZAÇÃO DAS RELAÇÕES COM O MERCADO NAS ORGANIZAÇÕES DE PRODUTORES DO SUL DO BRASIL
}

\author{
AGROECOLOGÍA, AGRICULTURA ORGÁNICA E \\ INSTITUCIONALIZACIÓN DE LAS RELACIONES CON EL MERCADO EN \\ LAS ORGANIZACIONES DE PRODUCTORES DEL SUR DEL BRASIL.
}

\author{
AGROECOLOGY, ORGANIC AGRICULTURE AND THE \\ INSTITUTIONALIZATION OF RELATIONS WITH THE MARKET IN \\ ORGANIZATIONS OF PRODUCERS IN THE SOUTH OF BRASIL
}

\author{
Prof. Dr. Glauco Schultz ${ }^{1}$ \\ glauco@bewnet.com.br
}

Resumo: O presente artigo propõe uma discussão sobre a agricultura orgânica e as relações com o mercado nas organizações de produtores, buscando identificar as oportunidades de agregação de valor aos produtos. Para cumprir com esses objetivos foram analisadas as percepções e os significados atribuídos pelos agricultores às diferentes estratégias de comercialização adotadas pelas organizações em que estão inseridos. Foram selecionadas para estudo sete organizações de agricultores nos três Estados da Região Sul do Brasil. Para o levantamento das informações junto a estas organizações, foram utilizadas, principalmente, fontes primárias, tais como entrevistas em profundidade e documentos. Para apoiar essa análise utilizou-se a Teoria Institucional, bem como os conceitos de Agroecologia e as definições de Agricultura Orgânica. Foi possível identificar o sentido das relações com o mercado na agricultura orgânica. As referências para esse processo de institucionalização estão baseadas na construção social da noção de qualidade dos alimentos, destacando-se os valores associados a biodiversidade (sustentabilidade) e ao acesso aos mercados (autenticidade), aspectos esses que vinculam-se à abordagem da segurança alimentar.

Palavras-Chave: agricultura orgânica; relações com o mercado; agroecologia; segurança alimentar; organizações de agricultores.

Resumen: El presente artículo propone una discusión sobre la agricultura orgánica y las relaciones con el mercado en las organizaciones de productores, tratando de identificar las oportunidades de agregación del valor a los productos. Para cumplir con estos objetivos se analizaron las percepciones y los significados atribuidos por los agricultores a las diferentes estrategias de comercialización adoptadas por las organizaciones en las cuales están inseridos. Se seleccionaron para dicho estudio siete organizaciones de agricultores en los tres Estados de la Región Sur del Brasil. Para el análisis de las informaciones a cerca de estas organizaciones, se emplearon principalmente fuentes primarias, como entrevistas hechas con profundad $\mathrm{y}$

\footnotetext{
${ }^{1}$ Programa de Pós - Graduação em Ambiente e Desenvolvimento Centro Universitário Univates - Lajeado/RS
} 
documentos. Para fundamentar este análisis se utilizaron la Teoría Institucional, los conceptos de Agroecología y las definiciones de Agricultura Orgánica. Fue posible identificar el sentido de las relaciones con el mercado en la agricultura orgánica. Las referencias para ese proceso de institucionalización están basadas en la construcción social de la noción de cualidad de los alimentos, destacándose los valores relacionados a la biodiversidad (sustentabilidad) y al acceso a los mercados (autenticidad), aspectos estos que se vinculan al abordaje de la seguridad alimenticia.

Palabras Llaves: agricultura orgánica; relaciones con el mercado; agroecología; seguridad alimenticia; organizaciones de agricultores.

\begin{abstract}
The main thrust of this article is to propose a discussion concerning organic agriculture and its relationship to the market within specific Brazilian organizations of producers; there is also here an attempt to identify any opportunities for adding value to their products. In order to accomplish this objective, an analysis was performed of the agriculturists' perceptions as well as the values they attribute to the different commercialization strategies adopted by those organizations to which they belong. For this study seven organizations of agriculturists in the three southern states of Brasil were selected. For the collecting of information concerning these groups primary sources (such as in-depth interviews and various documents) were used. To support this analysis the Institutional Theory was employed as well as the concept of Agroecology and the definitions of Organic Agriculture. It was also possible to define the market relationships within organic agriculture. The references for this institutionalization process are based in the social perceptions of the concept of food quality, especially the values associated with biodiversity (sustainability) and access to the market (authenticity) - characteristics that are connected to the concept of food security.
\end{abstract}

Keywords: organic agriculture; relationships with the market; agroecology; food security; organizations of agriculturists.

\title{
1 INTRODUÇÃO
}

A agricultura orgânica oportuniza a revisão das relações de cooperação e de competitividade no agronegócio brasileiro, possibilitando, desta forma, o estabelecimento de um relativo equilíbrio de forças entre os agentes das cadeias produtivas de alimentos, por meio de estratégias associadas às mudanças nos padrões de consumo e da conscientização ecológica. Trata-se de uma proposta de revisão das formas de produção, onde a busca pelo desenvolvimento deverá ocorrer sem a destruição dos recursos naturais. Entretanto, as agriculturas denominadas de "alternativas"

\footnotetext{
2 Agricultura alternativa é definida como aquela em que a divisão do trabalho na propriedade é modificada, em relação ao modelo convencional, alterando e diferenciando as características técnicas,
} 
e econômicos no meio rural, mas também incorporam, em suas discussões e práticas, as dimensões sociais e políticas que interferem na sustentabilidade dos sistemas produtivos. A agricultura orgânica assume maior legitimidade com a crescente preocupação da opinião pública a respeito dos impactos ambientais. O seu conceito e a sua prática atuais estão presentes no debate das questões relacionadas à noção de “desenvolvimento sustentável”. As características da agricultura orgânica refletem os contornos das amplas discussões sobre a preservação ambiental, que emergem a partir de 1960.

Cabe destacar, nesta trajetória de construção de uma nova visão sobre o meio ambiente, o Relatório "Nosso Futuro Comum", publicado em 1987 pela Comissão Mundial sobre Meio Ambiente e Desenvolvimento. Segundo este relatório, o Desenvolvimento Sustentável é aquele que garante o atendimento das "necessidades do presente sem comprometer a capacidade de as gerações futuras atenderem também às suas" (COMISSÃO MUNDIAL SOBRE MEIO AMBIENTE E DESENVOLVIMENTO, 1991:9). Este conceito traduz a prioridade de satisfazer as necessidades das camadas mais pobres da população e de minimizar os impactos dos modelos vigentes de produção sobre o meio ambiente, a partir da revisão das limitações impostas pelas tecnologias e pelas organizações sociais.

A agricultura orgânica ${ }^{3}$ se insere nesta ampla definição, fundamentada, principalmente, nas dimensões técnico-agronômicas de produção e de manejo dos agroecossistemas. Entretanto, em anos mais recentes, outros aspectos começaram a ganhar espaço nestas discussões. As relações com o mercado, estabelecidas pelas organizações de agricultores, presentemente ocupam, no Brasil, uma posição central nas discussões do denominado "movimento orgânico". As organizações de agricultores estabelecem diferentes relações com o mercado, destacando-se as seguintes: feiras livres, cestas de entrega em domicílio, lojas especializadas, supermercados, exportação,

sociais, econômicas e culturais dos sistemas de produção (ALMEIDA, 1998). Essa denominação foi muito utilizada nas décadas de 1960 e 1970, para caracterizar as formas sociais de agriculturas "diferenciadas", baseadas, principalmente, na inserção mais justa e solidária dos agricultores e consumidores no mercado.

3 Para o presente artigo utiliza-se a definição de agricultura orgânica ou sistema orgânico de produção, conforme estabelecido na Lei Federal 10.831 de dezembro de 2003. O conceito estabelecido nesta legislação busca contemplar as diversas correntes denominadas de "agriculturas alternativas", tais como "ecológico", "biodinâmico", "natural”, "regenerativo", "biológico", "agroecológico", "permacultura”, entre outros. 
agroindústrias e o denominado "mercado institucional", ou seja, o de compras governamentais. Portanto, torna-se fundamental, conhecer as características ora vigentes das diferentes estratégias com relação ao mercado estabelecidas por essas organizações.

Este artigo possui como objetivo identificar o sentido das relações com o mercado estabelecidas pelas organizações de agricultores que atuam com produção orgânica, a partir da análise das estratégias de comercialização e das fontes de agregação de valor aos produtos orgânicos. Para cumprir com esses objetivos foram estudadas as duas principais formas de comercialização (feiras livres e supermercados) em sete organizações de agricultores que atuam com produção orgânica no Sul do Brasil.

Os apelos inerentes à produção e ao consumo dos alimentos orgânicos induzem ao estabelecimento destas relações diferenciadas com o mercado. Sob esta perspectiva, a agricultura orgânica está inserida nas tendências atuais de sustentabilidade ambiental, de consumo consciente, de desenvolvimento territorial, de responsabilidade social, de segurança alimentar, de inclusão social, de agregação de valor para a agricultura familiar e de promoção da participação e da autogestão no meio rural. São estes aspectos, de crescente valorização pela sociedade, que possibilitam o crescimento do mercado, interno e externo, para os produtos ditos "orgânicos". A partir da década de 80, foi iniciado um processo acelerado de crescimento da produção e de consumo de produtos orgânicos.

A agricultura orgânica atualmente está presente em aproximadamente 120 países, envolvendo 623.174 propriedades, totalizando mais de 31 milhões de hectares, com 31\% na Austrália/Oceania, 21\% na Europa, 20\% na América Latina, 13\% na Ásia e 4\% na América do Norte (WILLER; YUSSEFI, 2006). O crescimento da produção orgânica no mundo apresenta taxas elevadas, considerando que em 2000, segundo Willer e Yussefi (2002), a área total era de aproximadamente 10 milhões de hectares. Os países que possuem maior quantidade de área com produção orgânica são a Austrália com 12,1 milhões de hectares, a China com 3,5 milhões e a Argentina com 2,8 milhões.

O mercado mundial de produtos orgânicos é estimado em US\$ 27,8 bilhões, sendo que mais de $50 \%$ deste (US\$ 14,5 bilhões) está concentrado no Estados Unidos. 
(WILLER; YUSSEFI, 2006). Segundo M. Fonseca (2005), citando dados do ITC (sigla, ?), o mercado de produtos orgânicos no mundo cresceu 23\% ao ano entre 1997 e 2001, sendo que os países que comercializam em supermercados apresentaram as taxas de crescimento mais significativas, principalmente na União Européia.

No Brasil, a produção orgânica apresentou um crescimento significativo nos últimos cinco anos, passando de 100 mil hectares em 2000 para 887.637 hectares em 2006. (WILLER; YUSSEFI, 2000, 2006). Considerando somente a produção formalmente certificada as vendas desses produtos no Brasil, em 2003, atingiram aproximadamente US\$ 200 milhões, com uma taxa de crescimento do mercado estimada entre 30 a 50\%. (LENOURD; PIOVANO, 2004). Abacaxi, banana, café, mel, leite, carnes, soja, palmito, açúcar, frango e hortaliças são alguns dos principais produtos da agricultura orgânica brasileira. Atualmente, no Brasil, já são aproximadamente 14.000 propriedades que possuem sistemas orgânicos de produção (WILLER; YUSSEFI, 2006), sendo que 90\% destes estão localizados em propriedades familiares.

Dessa produção, aproximadamente $90 \%$ é exportada como matéria prima, principalmente para os Estados Unidos, União Européia e Japão, sendo estes os maiores mercados compradores de produtos orgânicos brasileiros, tais como a banana, soja e café. Além disso, o Brasil se destaca na exportação de suco de laranja e açúcar orgânico. Com relação ao açúcar, Fonseca (2005) cita o exemplo da Usina São Francisco (Grupo Balbo), em Sertãozinho/SP, que se tornou o maior produtor e exportador de açúcar orgânico do mundo, detendo mais de $50 \%$ da produção mundial.

A comercialização no mercado interno concentra-se em supermercados, atingindo um percentual de $45 \%$ do total, sendo que as feiras e as lojas especializadas representam, respectivamente, $26 \%$ e 16\%. (LENOURD; PIOVANO, 2004) Os principais produtos comercializados no mercado interno são as hortaliças e as frutas, existindo uma tendência de crescimento da oferta dos produtos industrializados, principalmente, chás, óleos, cereais e derivados de leite. A produção animal, apesar do grande potencial do país, ainda é bastante baixa, e está concentrada em algumas poucas propriedades. O Brasil já conta com 21 entidades credenciadas para a certificação de produtos orgânicos, sendo 12 nacionais e 9 internacionais (LENOURD; PIOVANO, 
2004).

O setor de orgânicos se encontra em um contexto favorável de crescimento, que não está somente associado às demandas dos consumidores, mas que também está inserido nas estratégias de concorrências do setor varejista brasileiro. Conforme pesquisa realizada no Rio de Janeiro, por Guivant et al. (2003), em quatro redes varejistas de verduras e legumes, foi possível encontrar mais marcas orgânicas do que de outros produtos concorrentes convencionais. Nesta pesquisa, foram identificadas oito marcas de produtos orgânicos, sete de convencionais e quatro de hidropônicos. Esta proporção poderia ser interpretada com uma tendência de ecologização da oferta destes produtos, mas trata-se de uma estratégia de diferenciação, com apelos de produtos saudáveis, voltada para um público de alta renda e preocupado com a sua saúde, residentes, principalmente, em certos bairros do Rio de Janeiro (GUIVANT et al., 2003).

As significativas taxas de expansão mercadológica e o crescimento da produção orgânica no Brasil se explica devido ao estabelecimento de variadas estratégias empresarias, mas também devido às relações institucionais e às políticas públicas de apoio e promoção a este segmento do agronegócio brasileiro. A legitimidade da agricultura orgânica, como sistema de produção voltado para a viabilização da sustentabilidade do meio rural, assume um papel de destaque no cenário das "alternativas" propostas para a promoção de políticas públicas direcionadas para a agricultura familiar.

Este artigo está dividido em 04 seções além dessa introdução. Na seção 2 é apresentado o referencial teórico relacionado à Teoria Institucional, à Agroecologia e à Agricultura Orgânica. O Método de Pesquisa é apresentado na seção 3 e as estratégias de comercialização e oportunidades de agregação de valor na seção 4. Por fim, na seção 5 apresenta-se as conclusões do artigo, contendo a discussão sobre o sentido das relações com o mercado na agricultura orgânica. 


\section{REFERENCIAL TÉORICO}

Nessa seção é apresentada o Referencial Teórico que proporcionou a análise das informações coletadas junto às organizações de agricultores. A Teoria Institucional, baseada na sociologia das organizações, a Agroecologia como ciência para análise dos agroecossistemas e a Agricultura Orgânica como proposta técnica de produção, constituem-se em um conjunto de referenciais que apoiaram a presente análise sobre o sentido das relações com o mercado na agricultura orgânica.

\subsection{Teoria Institucional}

A Teoria Institucional é uma das abordagens teóricas que têm contribuído para o entendimento de fenômenos sociais. As representações que os atores constróem sobre o ambiente em que estão inseridos são consideradas como o fio condutor do referencial teórico do artigo aqui apresentado.

Neste sentido, Vieira e Carvalho (2003:12) entendem que "as organizações sobrevivem ao compartilharem valores em um determinado espaço social", em contraposição às relações unicamente de caráter técnico e econômico. Desta concepção, decorre que as organizações são influenciadas por um conjunto de aspectos interpretativos dos atores internos e externos sobre o contexto em que estão inseridos. Tais representações e interpretações resultam em referenciais de valores que moldam as identificações dos atores, e, ao mesmo tempo, fornecem sentido às suas ações e práticas individuais e coletivas, dentro das suas respectivas organizações.

A Teoria Institucional é bastante abrangente, incorporando contribuições principalmente da economia, da sociologia e da ciência política, variando consideravelmente os níveis de análise e os métodos de pesquisa. Estas áreas de conhecimento " [...] buscam incorporar, em suas proposições, a idéia de instituições e de padrões de comportamento, de normas e de valores, de crenças e de pressupostos, nos quais se encontram imersos indivíduos, grupos e organizações" (MACHADO-DASILVA; GONÇALVES, 1999:220). 
A teoria institucional oferece importantes elementos para o entendimento do ambiente em que as organizações estão inseridas e de como estas se adaptam ou resistem às mudanças e pressões externas. $\mathrm{O}$ principal argumento apresentado pelas abordagens institucionais, vinculadas às ciências organizacionais, é o de que as organizações reagem ou resistem à mudança de sua estrutura não somente em função de necessidades e decisões técnicas e econômicas, em busca da melhor eficiência, mas também, ou unicamente, por necessidades e estratégias de legitimação, no ambiente em que estão inseridas.

A abordagem acima incorpora aspectos culturais e políticos na definição das estratégias organizacionais, afastando-se, portanto, das explicações puramente técnicas e econômicas para as configurações e o comportamento organizacional. De acordo com a abordagem institucionalista, as organizações estão inseridas em um ambiente constituído por regras, crenças, valores e elementos sociais, culturais e cognitivos, que são criados e consolidados por meio da interação social. Surge, portanto, como uma nova forma de analisar o ambiente e os aspectos internos e externos em que os agentes econômicos estão inseridos, a partir de novos fatores, que afetam diretamente os resultados das organizações. As oportunidades no ambiente são originadas não somente através das restrições tradicionais da teoria econômica, mas também pelas restrições institucionais.

Zucker e Tolbert (1999:196) afirmam que existem vários trabalhos sob o enfoque da teoria institucional que buscam o entendimento, por exemplo, das políticas de pessoal nas empresas, da estrutura e missão das organizações e da formulação de políticas por parte de governos. "[...] no entanto, ironicamente, a abordagem institucional ainda há que se tornar institucionalizada.”. Isto se deve, segundo estas autoras, à falta de consenso sobre os conceitos associados à teoria, e à inexistência de variáveis e métodos consolidados de pesquisa, mas que não está impedindo o grande interesse pelo estudo da institucionalização das organizações, como forma explicativa dos fenômenos associados à complexidade empresarial.

As contribuições para a análise das estruturas organizacionais, a partir de uma visão institucionalista, tiveram início com Meyer e Rowan (1999). A preocupação destes autores, ao escreverem o artigo Institutionalized Organizations: formal structure as 
myth and ceremony, em 1977, foi o de estudar as características simbólicas (mitos e cerimônias) e o modo como estas se refletem na (ou contribuem para a) formação das estruturas organizacionais. Neste sentido, "Muitos elementos da estrutura formal estão altamente institucionalizados e funcionam como mitos" (MEYER; ROWAN, 1999:83). Os mitos a que se referem os autores estão relacionados aos posicionamentos políticos, à opinião pública, ao conhecimento legitimado e às leis, consistindo em um conjunto de regras institucionais incorporadas na realidade social, que moldam as condutas organizacionais, ou seja, as organizações refletem de modo estrutural a realidade construída socialmente.

O estabelecimento das estratégias nas organizações ocorre com o objetivo fundamental de atingir uma legitimidade institucional. Machado-da-Silva e Fonseca (1999) afirmam que "as organizações estão inseridas em um ambiente construído por regras, crenças e valores, criados e consolidados por meio da interação social". Para estes autores, o "atendimento às orientações coletivamente compartilhadas" é que dá sustentação às estratégias implementadas, e o seu atendimento faz parte dos principais balizadores da análise da eficiência organizacional. De tal forma, a noção de competitividade, nas organizações, simplesmente se afasta da do desempenho atingido nos processos de gestão da produção e de alcance de melhores posições no mercado.

Scott e Meyer (1999) afirmam que as organizações podem estar inseridas em ambientes técnicos ou institucionais. Os ambientes técnicos estão relacionados aos mercados competitivos da economia neoclássica, onde a coordenação e o controle dos processos técnicos são centrais para as organizações. E os ambientes institucionais são compostos por um sistema de crenças generalizadas, que determina como as organizações devam se comportar. Conforme Scott e Meyer (1999:170) o ambiente técnico é definido como "aquele em que se produz e se transaciona um produto ou serviço em um mercado onde as organizações são recompensadas por um controle efetivo de seus sistemas de produção". E o ambiente institucional "se caracteriza por regras e requisitos aos quais as organizações devem se ajustar, se desejarem receber apoio e legitimidade".

Portanto, não são os aspectos técnicos e econômicos associados à melhor eficiência e desempenho competitivo no ambiente que definem as condutas do atores 
nas organizações. Antes mesmo disto, este determinante está na busca de legitimidade, baseada nas crenças e valores socialmente aceitos.

\subsection{Agroecologia e o Enfoque Científico}

A legitimação da definição de agroecologia como uma ciência, a partir da década de 80 do século passado, estabelece as bases teóricas para a consolidação das diferentes modalidades de agricultura alternativa. A agroecologia é considerada como uma disciplina científica de estudos dos agroecossistemas, e também um "guarda-chuva" conceitual, que acolhe as diversas correntes alternativas da agricultura. Entretanto, esta imprecisão na definição da agroecologia parece ter sido superada, apesar das suas diversas utilizações em variados contextos e situações.

Segundo Assis (2002:15), a agroecologia busca resgatar "a lógica da complexificação das sociedades camponesas tradicionais e dos seus conhecimentos, que haviam sido desprezados pela agricultura moderna", incorporando princípios ecológicos, agronômicos e socioeconômicos para um melhor entendimento dos efeitos das tecnologias, tanto nos sistemas de produção quanto nas transformações da sociedade que sejam decorrentes destas tecnologias. $\mathrm{O}$ entendimento do funcionamento dos agroecossistemas é central na agroecologia. Este entendimento tem, como pressuposto básico, a diversificação da produção como forma de garantir a sustentabilidade. Os maiores avanços, entretanto, parecem estar relacionados à discussão das relações entre a agronomia e a ecologia, destacando-se as contribuições dos trabalhos de Miguel Altieri e Stephen Gliessman (CAPORAL \& COSTABEBER, 2002).

Segundo Altieri (1998:18), que foi um dos precursores da defesa da agroecologia como uma ciência, "trata-se de uma nova abordagem que integra os princípios agronômicos, ecológicos e socioeconômicos à compreensão e à avaliação do efeito das tecnologias sobre os sistemas agrícolas e a sociedade como um todo". A agroecologia possui como objetivo o estudo da agricultura sob a perspectiva da ecologia, podendo ser, portanto, denominada também de "ecologia agrícola". A agroecologia é uma abordagem teórica que contribui para o entendimento dos possíveis modos de otimização dos agroecossistemas, considerando os seus ciclos minerais, seus fluxos 
energéticos, seus processos biológicos e suas relações socioeconômicas, ou seja, que analisa as "interações complexas entre pessoas, culturas, solos e animais" (ALTIERI, 1989:18). Hecht (1989:25-31) afirma que "o uso contemporâneo do termo agroecologia data dos anos 70 , mas a ciência e a prática da agroecologia têm a idade da própria agricultura". Segundo Caporal e Costabeber (2002), a sustentabilidade dos agroecossistemas, baseado nos princípios, conceitos e metodologias da agroecologia, pode ser avaliada por um conjunto de dimensões que se inter-relacionam e que auxiliam na definição de indicadores de sustentabilidade.

A partir da abordagem multidimensional da sustentabilidade (ecológica, econômica, social, política, cultural e ética) o paradigma agroecológico ou a agroecologia como um enfoque científico se diferencia, conceitual e significativamente, de outras abordagens relacionadas à agricultura sustentável. As diferentes definições utilizadas atualmente devem ser melhor interpretadas, e, através desta reinterpretação, a agroecologia poderá ser melhor localizada, no âmago desta ampla discussão. Portanto, a agroecologia não pode ser considerada como um mercado, um sistema de produção, um modelo tecnológico, ou como uma política pública, mas antes, como um enfoque científico que dá sustentação à elaboração de estratégias de sustentabilidade na agricultura.

\subsection{Agricultura Orgânica e o Enfoque Técnico}

As propostas pioneiras, ou as "teorias clássicas" da agricultura ecológica, possuem suas origens principalmente em aspectos técnicos, tais como adubação orgânica e rotação de culturas. Entretanto, a associação entre filosofia, espiritualismos, religião e política (autonomia dos produtores e comercialização direta) é também uma identificadora destas correntes pioneiras da agricultura "diferente" do modelo convencional, já nas décadas de 20 e 30 do século passado. Apesar de a sustentação das propostas receber aportes conceituais e teóricos de disciplinas filosóficas e religiosas, é da experimentação agronômica que vem o maior sustentáculo daquelas manifestações pioneiras do campo da agricultura, enquanto constituindo uma alternativa ao modelo químico, mecânico e de melhoramento genético. 
Algumas das principais "correntes" surgiram quase que simultaneamente na década de 20, e agrupam-se em quatro grandes vertentes, segundo Ehlers (1996): na Alemanha, foi desenvolvida a agricultura biodinâmica, iniciada por Rudolf Steiner, em 1924; na Inglaterra, foi estabelecida a agricultura orgânica, cujos princípios foram estabelecidos entre os anos de 1925 e 1930, pelo pesquisador Sir Albert Howard, sendo após, na década de 40, difundidos nos EUA, por Jerome Irving Rodale; na Suíça, no início dos anos 30, surgiu a agricultura biológica, baseada nos princípios criados por Hans Peter Müller, sendo mais tarde difundida na França por Claude Aubert; e no Japão, a partir de 1935, foi elaborada outra vertente, baseada nas idéias de Mokiti Okada, chamada de agricultura natural.

Ehlers (1996) denomina estas correntes pioneiras de "movimentos rebeldes", por se contraporem à agricultura com adubação química, sendo que estas, bem como outras que surgiram posteriormente, possuem seus princípios baseados na "Primeira Revolução Agrícola"4, tais como a rotação de culturas e a integração entre as produções animal e vegetal. Entretanto, desde a sua divulgação inicial, estes sistemas de produção ficaram à margem do processo de desenvolvimento das práticas agrícolas. A partir da década de 60, quando foi intensificado o uso de práticas mais modernas, através da chamada "Revolução Verde ${ }^{5 "}$, e começaram a ser mais amplamente divulgados os impactos sobre o meio ambiente, estas propostas técnicas de produção ganharam mais força, enquanto alternativas ao modelo atual.

Aquelas correntes pioneiras deram origem a outras propostas de produção agrícola, ou, como afirma Daroldt (2002), foram desenvolvidas novas denominações e outros termos ou filosofias que reúnem correntes que se diferenciam da agricultura convencional. Seguindo esta linha histórica, tem-se a permacultura, a agricultura regenerativa, a teoria da trofobiose e os sistemas agroflorestais. Discussões sobre as

\footnotetext{
${ }^{4}$ Ehlers (1986) refere-se à Primeira Revolução Agrícola como o período de profundas transformações no sistema de produção agrícola, ocorridas nos séculos XVIII e XIX na Europa Ocidental, dando início à agricultura moderna. Caracteriza-se pela aproximação entre as atividades agrícola e pecuária, o que proporcionou o aumento da escala de produção e a diminuição da escassez de alimentos.

${ }^{5}$ A "Revolução Verde" refere-se às mudanças ocorridas, após a segunda guerra mundial, nos sistemas de produção agrícola, com o objetivo de aumentar a produtividade dos cultivos, a partir da adoção de um "modelo químico, mecânico e genético" de produção. Caracteriza-se pela introdução de novas tecnologias, principalmente relacionadas ao melhoramento genético das plantas, e da ampliação e intensificação na utilização de fertilizantes químicos, agrotóxicos, irrigação e de máquinas e equipamentos nas propriedades. Atualmente, após a consolidação dessas mudanças nas atividades rurais, esse modelo de produção é mais conhecido como agricultura convencional.
} 
principais escolas ou correntes e os seus principais autores podem ser encontradas em Ehlers (1996), Canuto (1998), Paulus (1999), Dulley (2003) e Daroldt (2002a).

No Brasil utiliza-se, principalmente, a definição de "sistema orgânico de produção", conforme estabelecido na Lei Federal 10.831, de dezembro de 2003. Esta lei, por sua vez, busca contemplar todas as denominações relacionadas acima:

[...] todo aquele em que se adotam técnicas específicas, mediante a otimização do uso dos recursos naturais e socioeconômicos disponíveis e o respeito à integridade cultural das comunidades rurais, tendo por objetivo a sustentabilidade econômica e ecológica, a maximização dos benefícios sociais, a minimização da dependência de energia não-renovável, empregando, sempre que possível, métodos culturais, biológicos e mecânicos, em contraposição ao uso de materiais sintéticos, a eliminação do uso de organismos geneticamente modificados e radiações ionizantes, em qualquer fase do processo de produção, processamento, armazenamento, distribuição e comercialização, e a proteção do meio ambiente. (BRASIL, 2003).

O conceito de sistema orgânico de produção agropecuária e industrial abrange os denominados: "ecológico"; "biodinâmico"; "natural"; "regenerativo"; "biológico"; "agroecológicos"; "permacultura", bem como outros que atendam os princípios estabelecidos por esta Lei.

\section{Método de PeSQuisa}

A questão principal está relacionada às percepções e aos significados atribuídos pelos agricultores às diferentes estratégias de comercialização, tendo como objetivo identificar o sentido das relações com o mercado na agricultura orgânica. Dessa forma, a pesquisa teve o propósito de identificar organizações que representassem os principais canais de comercialização existentes atualmente: supermercado; feira livre; mercado institucional; e lojas de produtos naturais e integrais. Entretanto, a presente análise concentra-se sobre duas formas preominantes de comercialização identificadas no mercado interno: feiras - livres e supermercados. Para isso, foram selecionadas, a partir da representatividade dessas duas relações com o mercado, sete organizações (cooperativas e associações) de agricultores envolvidos com produção orgânica, nos Estados do RS, SC e PR, apresentadas abaixo: 
AGRECO - Associação dos Agricultores Ecológicos das Encostas da Serra Geral - foi fundada em dezembro de 1996, e está localizada no município de Santa Rosa de Lima, município com 2 mil habitantes (distante $140 \mathrm{~km}$ de Florianópolis) da região das Encostas da Serra Geral de Santa Catarina. São 97 sócios, em 44 propriedades certificadas, sendo que 22 destes possuem agroindústrias familiares. Principais formas de comercialização: supermercados e mercado institucional

APAC - Associação de Produtores Agrícolas de Colombo - foi fundada há 21 anos, em outubro de 1984, e está localizada no município de Colombo (220 mil habitantes) na região metropolitana de Curitiba - PR. São 102 sócios, sendo 23 agricultores que possuem propriedades certificadas com produtos orgânicos e 20 outros que estão em processo de conversão. Principal forma de comercialização: supermercados.

ECOCITRUS - Cooperativa de Citricultores Ecológicos do Vale do Caí - foi fundada em 1994, e está localizada no município de Montenegro, distante $60 \mathrm{~km}$ de Porto Alegre - RS. A sua abrangência é regional, por envolver 43 sócios e 30 propriedades certificadas, em seis municípios da Região do Vale do Caí. Principais formas de comercialização: supermercados e mercado institucional.

\section{ARPASUL - Associação Regional de Produtores Agroecológicos da Região} Sul - foi fundada em 1995 e reúne 35 famílias de agricultores que atuam com produção orgânica, em 5 municípios da Região Sul do Estado do RS. Principal forma de comercialização: feiras-livres.

COPAÉCIA - Cooperativa Aécia de Agricultores Ecologistas - está localizada no município de Antônio Prado (distante $200 \mathrm{~km}$ de Porto Alegre), e foi fundada em 1991, reunindo 22 agricultores dos municípios de Ipê e Antônio Prado. Principais formas de comercialização: pequenas lojas, feiras-livres e mercado institucional.

AOPA/MBA - Associação de Agricultura Orgânica do Paraná/ Núcleo Maurício Burmester do Amaral - o núcleo MBA foi fundado em 2002 e é formado por 18 grupos de agricultores localizados em 20 municípios do Estado do Paraná, 
integrando em torno de 180 famílias. Principais formas de comercialização: feiras-livres e cestas de produtos.

\section{COOPAFE - Cooperativa de Agricultores Familiares do Sudoeste do} Paraná/Grupo de Agricultores Ecológico de Capanema/PR - fundada em 2005, reunindo 30 famílias de agricultores que atuam com produção orgânica no município de Capanema/PR. Principal forma de comercialização: supermercado (próprio).

Para o levantamento das informações junto a estas organizações, foram utilizadas principalmente fontes primárias, tais como entrevistas e documentos. Também foram utilizados documentos internos e material de divulgação das organizações e das instituições de apoio, tais como as atas de reuniões, relatórios, estatutos, textos de discussão, planejamentos anuais, projetos, documentação histórica, entre outros.

As entrevistas constituíram a principal fonte primária utilizada, sendo realizadas com os agricultores e em todos os casos, se buscou selecionar informantes qualificados, responsáveis pela elaboração ou implementação das estratégias nas organizações de produtores (líderes ou gestores), bem como técnicos representantes das relações institucionais estabelecidas pelas organizações de produtores. Conseqüentemente, foram utilizados dois principais instrumentos para o levantamento das informações primárias: análise de documentos e entrevistas em profundidade (gravadas) com a utilização de roteiros estruturados.

Como resultado da diversidade de realidades nas organizações estudadas foram realizadas 46 entrevistas em profundidade (aproximadamente com duração de 01 hora cada uma) buscando contemplar agricultores, lideranças nas organizações de produtores, técnicos, pesquisadores, representantes de instituições parceiras e gestores/articuladores de políticas públicas para o setor. Essas entrevistas foram realizadas em dois momentos: em outubro de 2005 e em março de 2006.

A abordagem de pesquisa adotada, sendo qualitativa, não requer a preocupação em medir as variáveis e indicadores utilizados e, tampouco, o emprego de análise estatística. $\mathrm{Na}$ análise das informações, se buscará identificar a presença ou ausência 
dos fenômenos ou elementos associados às variáveis e indicadores, não considerando a freqüência com que os mesmos ocorrem.

Na literatura sobre as abordagens qualitativas (YIN, 2005; ALVES-MAZZOTTI; GEWANDSZNAJDER, 2004; VIEIRA; ZOUAIN, 2004), encontra-se uma maior ênfase em indicações de princípios e estratégias para aumentar a confiabilidade da pesquisa, que estão baseadas principalmente no rigorismo com que o pesquisador conduz o estudo e apresenta os resultados, e muito menos em opções de técnicas de análise que busquem apresentar os procedimentos e instrumentos necessários para a interpretação dos dados coletados.

Com as informações disponíveis, foi realizada, fundamentalmente, uma triangulação entre as várias fontes de informações e de evidências sobre os fenômenos estudados. Portanto, a análise de documentos e das entrevistas em profundidade, bem como a observação direta, sendo postas ambas em confronto com o referencial teórico, constituíram a principal "técnica" para a análise dos dados. A triangulação, segundo Vieira e Zouain (2004:23), é importante para diminuir a “[...] influência dos vieses do pesquisador no resultado final das análises.”, utilizando o "[...] processo de checagem, questionamento e teorização [...]”, o que proporciona validades interna e externa, credibilidade e confiabilidade da pesquisa qualitativa, e, conseqüentemente, transferibilidade e utilização dos resultados para o avanço do conhecimento.

\section{Estratégias de Comercialização e Oportunidades de Agregação de VAlOR AOS Produtos Orgânicos}

Nessa seção são apresentadas as reflexões sobre as estratégias de mercado adotadas pelas organizações estudadas, centrando a análise nas formas predominantes de comercialização (feiras livres e supermercados), buscando identificar as oportunidades de agregação de valor aos produtos orgânicos.

As análises apresentadas abaixo estão baseadas em entrevistas realizadas com agricultores que atuam com produção orgânica junto às cooperativas e associações de produtores. A partir das percepções dos agricultores sobre as estratégias de 
comercialização adotadas pelas organizações em que estão inseridos, foi possível interpretar o sentido das relações com o mercado na agricultura orgânica, aspectos esses que são apresentados na última seção (conclusão). Cabe destacar que trata-se de uma análise sobre a realidade da Região Sul do Brasil. Entretanto, é possível que muitos dos aspectos aqui apresentados estejam presentes em organizações localizadas em outras regiões brasileiras, mas que são merecedoras de reflexões específicas sobre essas diferentes realidades.

Os grifos (aspas) utilizadas ao longo do texto referem-se às expressões utilizadas pelos agricultores, optando-se por destacá-la com o objetivo de preservar o sentido das reflexões proporcionadas pelos entrevistados.

\subsection{Feiras livres}

Os apelos inerentes à produção e ao consumo dos alimentos orgânicos induzem ao estabelecimento de relações diferenciadas com o mercado. O próprio canal de comercialização utilizado pode contribuir para a formação desta valorização associada aos produtos orgânicos. As dificuldades de construir relações diferenciadas com o varejo convencional é o que torna a feira livre um espaço importante para viabilização de uma comercialização mais justa.

A comercialização direta é uma forma de afirmação das conquistas dos grupos analisados em um segmento de mercado em expansão, não se identificado nas entrevistas a percepção comum sobre as dificuldades da realização da comercialização em feiras (existem, mas não a ponto de causarem baixos desempenhos), quanto aos aspectos de volumes, logística, diversificação e envolvimento dos agricultores e de sua família. Os aspectos positivos ressaltados dizem respeito a faturamentos semanais, contato direto com os consumidores e divulgação constante do trabalho com a agricultura ecológica.

A comercialização direta, através de feiras livres, constitui-se em uma forma predominante de distribuição dos produtos orgânicos nas organizações estudadas. A determinação desses grupos de agricultores em dar continuidade às formas de 
comercialização direta, em muito recebem o incentivo e o apoio institucional de prefeituras que buscam fortalecer espaços públicos (praças) de grande circulação de pessoas. Por exemplo, somente em Curitiba/PR já são seis feiras de produtos orgânicos localizadas nas principais praças da cidade.

Com isto, a comercialização em feiras também se constitui como um espaço cultural, educativo e de troca de informações, no sentido de enriquecer e de fortalecer as relações sociais. Além disto, a feira também tem como objetivo promover a comercialização de alimentos orgânicos a partir da "humanização" das relações comerciais, eliminando comerciantes intermediários. De tal forma, ocorre a integração e troca de experiências entre os produtores, sendo este o local, onde, também, se criam fortes vínculos entre os agricultores e os consumidores, resultando na construção de uma maior credibilidade no trabalho realizado. (SCHULTZ, 2006)

Uma outra constatação com relação às feiras livres, de uma forma geral, referese à credibilidade que a mesma apresenta para o mercado consumidor e revendedor de produtos orgânicos. O produtor que está comercializando os seus produtos no espaço da feira está inserido em uma rede que lhe fornece de fato um grau de credibilidade que atualmente está sendo interpretada como "certificação" pelos consumidores finais e para a revenda em outros locais. Além disso, este espaço pode ser considerado um local de promoção dos produtos, que viabiliza e potencializa as vendas em outros mercados, por possibilitar o encontro e a negociação permanente entre compradores e produtores. $\mathrm{Na}$ feira é possível divulgar a mensagem sobre os alimentos orgânicos diretamente aos consumidores por quem mais entende daquela produção. Isso ocorre através de conversas rápidas nos encontros semanais, evitando assim a utilização de apelos comerciais convencionais para atrair os consumidores para as compras.

A comercialização direta estabelece laços sociais com os consumidores, reforçando a garantia da qualidade dos produtos. Além disso, o contato com os consumidores proporciona a troca de informações que auxiliam o agricultor no planejamento da sua produção. Ressalta-se a credibilidade e a confiança que é gerada nesse contato direto com o consumidor, construído a partir de visitas às propriedades.

Os agricultores que comercializam os seus produtos em feiras expressam as suas 
estratégias de mercado através da ampliação e consolidação das relações diretas com os consumidores. A principal barreira para esta ampliação se encontra no aumento do número de agricultores, exigindo, no decorrer deste processo, uma maior capacidade de envolvimento e de manutenção de tais relações de interdependência.

A feira proporciona para os agricultores a possibilidade construção de novas relações com o mercado e de "apropriação do seu espaço", e também o "controle" sobre os mecanismos de mercado, tais como a definição dos preços e os faturamentos semanais. Portanto, para os agricultores, a feira é uma forma de gerar "autonomia" nas decisões, a partir das relações diretas com os consumidores, aspectos estes que são transpostos também para as relações com os supermercados, caso estas venham a ser estabelecidas. A feira livre possibilita, também, a geração de credibilidade junto ao mercado consumidor e revendedor de produtos orgânicos.

A ampliação do número de feiras fica comprometida em função dos baixos volumes de produção e da necessidade de diversificação nas propriedades. Para a realização das feiras, é fundamental a garantia da ampliação do número de famílias, o que proporcionaria a diversificação dos produtos comercializados e o aumento do tamanho da feira. Entretanto, este é um dos aspectos que apresenta problemas para reforçar esta estratégia de mercado.

Por outro lado, o crescimento do número de feiras nos últimos anos criando uma preocupação verificada junto a alguns produtores. Existe o risco de alguns produtores deixarem a produção de lado e se tornarem "comerciantes”, já que, segundo alguns depoimentos, é impossível produzir e comercializar em mais de duas feiras semanais. Se isso ocorre o produtor está se afastando dos princípios da agroecologia, gerando contradições no trabalho do agricultor, quando produzem somente para atender as demandas do mercado.

Os volumes de produção, a diversificação e a quantidade de feiras semanais requerem um significativo envolvimento dos agricultores, tanto na produção como na comercialização. De certa forma, esta potencial situação problemática é contornada com o rodízio entre os agricultores que participam das feiras. As dificuldades de serem garantidos volumes necessários para ampliação das feiras e ao mesmo tempo a 
diversificação da produção, contribuem para que esta relação com o mercado apresente limitações na capacidade de atendimento das demandas do mercado. Diante destas condições, as vantagens competitivas oriundas da relação direta com os consumidores ficam minimizadas.

Para a realização da feira, são necessários, além de um planejamento para "ter a seqüência na produção", diversificação da produção, o que implica a necessidade de maior disponibilidade de tempo e de mão-de-obra na propriedade. Os deslocamentos para transporte dos produtos e realização das feiras impactam significativamente nesse tempo disponível. Os agricultores, que estão envolvidos a mais tempo com este tipo de comercialização, tendem a buscar uma priorização nas atividades, para, com isto, "poder atender a tudo".

\subsection{Supermercados}

No Brasil existe a tendência e ocorrer a concentração da comercialização dos produtos orgânicos em supermercados, principalmente nos maiores centros consumidores. Trata-se de um canal de comercialização que está influenciando e determinando a demanda e produção de produtos orgânicos. A comercialização em supermercado torna "mais evidente" o produto orgânico, sendo assim uma oportunidade de ampliar a sua visibilidade e de demonstrar os seus mais diversos atributos.

No Brasil, as estratégias de diferenciação dos supermercados, de uma forma geral, voltam-se principalmente para a oferta de produtos perecíveis, principalmente de frutas, legumes e verduras, pois as visitas dos consumidores são mais freqüentes (GUIVANT et al., 2003). São nestas condições que os produtos orgânicos ganham maior visibilidade dentro dos supermercados, buscando atrair, principalmente, os consumidores de maior renda.

Diante dessa estratégia voltada para os produtos perecíveis, principalmente nas frutas, legumes e verduras, os produtos orgânicos ganham maior visibilidade dentro das lojas das grandes redes varejistas de alimentos e sempre com objetivo de atrair os consumidores de maior renda. São programas e projetos das grandes redes varejistas de 
alimentos voltados para promoção da garantia da qualidade e origem dos produtos e onde os alimentos orgânicos se inserem como fundamentais, dentro de uma estratégia mais ampla de diferenciação do setor de perecíveis e atratividade dos consumidores para as suas compras freqüentes.

Portanto, como identificado por Guivant (2003), as estratégias dos grandes supermercados não estão voltadas para substituição dos alimentos oriundos da agricultura convencional ou uma "ecologização" da oferta e do consumo, mas sim numa diluição dos produtos orgânicos "numa oferta de produtos diversos associados com bem-estar, saúde e qualidade de vida"(GUIVANT, 2003:79).

Assim, segue a autora, os supermercados agem com o objetivo de atender ao denominado consumidor "ego-trip", caracterizado por possuir motivações para o consumo de alimentos orgânicos dentro de um conjunto de práticas consideradas saudáveis, sendo que os produtos orgânicos são considerados mais uma destas práticas.Os apelos dos consumidores desses produtos em supermercados não se referem apenas às preocupações ambientais e sociais, mas também à construção de um estilo de vida e de hábitos diários voltados para a saúde e prazer. Os consumidores de alimentos orgânicos, em supermercados, tendem a ser motivados para o consumo, portanto, por atributos pontuais, que podem existir em diversos tipos de outros produtos, e não pelos conceitos associados aos modos de produção orgânica.

As grandes redes varejistas, nos últimos anos, começaram a adotar uma estratégia pró-ativa em relação à implementação de programas de garantia da qualidade no setor de frutas, legumes e verduras, sendo feita, desta forma a inclusão dos produtos orgânicos nestas estratégias (GUIVANT et al., 2003). Os supermercados passam a fornecer selos de garantia ${ }^{6}$ para os produtos, através de parcerias com certificadoras de produtos orgânicos e por meio de contratação de equipe própria de profissionais para atuarem junto aos produtores.

\footnotetext{
${ }^{6}$ Estratégias mais agressivas, com relação aos produtos orgânicos e naturais, foram identificadas por Guivant (2003) em duas redes de supermercados. Nas lojas da rede Sendas, no Rio de Janeiro, onde a empresa lançou um marca própria para esses produtos, denominada de Bio Native, ela também realiza, aos sábados e domingos, a "Feira Orgânica", nas filiais de alguns bairros. O Carrefour possui o selo "Garantia de Origem Carrefour" voltado para diversos produtos, e não somente orgânicos, além de voltarse para a produção de uva de mesa orgânica e de carne orgânica, na Região do Vale do São Francisco e no Mato Grosso do Sul, respectivamente.
} 
A imagem que se consolida sobre os produtos orgânicos, junto aos consumidores, e também para os produtores é que trata-se de "uma coisa rara". O questionamento sobre os altos preços praticados pelos supermercados é feito pelos próprios produtores, percebendo que a estratégia volta-se para a definição de um tipo de consumidor exclusivo para esses produtos, onde somente um extrato muito pequeno da população consome esse tipo de produto, o que reforça a imagem de que os alimentos orgânicos, necessariamente, apresentam preços mais altos.

Fundamentalmente, percebe-se que a comercialização em supermercados proporciona aos agricultores a consolidação de uma imagem associada às suas atividades e aos produtos orgânicos (SCHULTZ, 2006). O supermercado é percebido pelos agricultores como um espaço que "tem tudo", suprindo dessa forma as necessidades dos consumidores, além da aquisição dos produtos orgânicos. A percepção sobre esta forma de comercialização vincula-se à tendência do varejo, de uma forma geral, de buscar garantir segurança e facilidade de acesso por parte dos consumidores.

Portanto, o supermercado é percebido como um contraponto à comercialização direta, já que as feiras não oferecem as condições adequadas para o acesso do "típico" consumidor dos produtos orgânicos, que é considerado de alta renda, e que por isto é exigente em relação aos produtos que adquire e aos serviços prestados durante as suas compras.

Os problemas oriundos da relação com os supermercados, relatados pelos agricultores, dizem respeito principalmente à devolução de produtos, às perdas decorrentes da não-comercialização, à impossibilidade de diferenciar os produtos no mercado e aos preços baixos recebidos. O sistema adotado pelos supermercados - de devolução dos produtos não vendidos - foi ressaltado por um dos entrevistados como uma "exploração violenta", aspecto este que é minimizado ao implantarem a produção de produtos não-perecíveis

A consolidação de uma imagem associada a uma marca, a partir das relações com os supermercados, parece compensar as perdas originadas por este tipo de relação com o mercado, pois os agricultores utilizam esta legitimidade para reforçar a 
viabilização de empreendimentos econômicos locais (SCHULTZ, 2006). Estes projetos podem ser voltados para o agroturismo, para o mercado institucional, para a construção de ecovilas e de agroindústrias.

Em síntese, as dificuldades ressaltadas pelos agricultores com relação as perdas e as devoluções, se refletem na percepção de que "o mercado é complicado", e por isto, "deveriam" existir alternativas de comercialização. A lógica do "mercado capitalista", mesmo garantindo a imagem no mercado de orgânicos, não fornece as condições necessárias para a valorização das suas atividades de produção. O supermercado é percebido como um "atravessador", como "alguém” que não valoriza o produto, que "tira" algo do produtor. Entretanto, as opções estratégicas com relação ao mercado são limitadas ou estão em processo de construção. Nos casos em que a produção é alta, e a comercialização ocorre em supermercados, não existe possibilidade de o agri=cultor se dedicar, também, às vendas diretas em feiras. O mercado, conforme constatado nas entrevistas, não permite a flexibilidade adequada para o produtor com relação à atuação na comercialização. A mudança, nesse caso, passa pela redefinição da lógica de produção, que atualmente está baseada, fundamentalmente, em um ou poucos tipos de cultivo.

\section{Conclusões}

A agricultura orgânica oportuniza a revisão das relações de cooperação e de competitividade no agronegócio brasileiro, possibilitando, desta forma, o estabelecimento de um relativo equilíbrio de forças entre os agentes das cadeias produtivas de alimentos, por meio de estratégias associadas às mudanças nos padrões de consumo e da conscientização ecológica.

A agricultura orgânica assume maior legitimidade com a crescente preocupação da opinião pública a respeito dos impactos ambientais. Além dos aspectos ambientais associados aos produtos orgânicos, esses novos valores também incluem a solidariedade, os processos participativos e de resgate da cidadania, os mercados alternativos, a certificação e a rastreabilidade dos alimentos, que se fundamentam nos aspectos relacionados à higiene e à reeducação alimentar (SCHULTZ, 2006). 
A transformação destes aspectos em estratégias empresariais, no âmbito das organizações de agricultores que atuam com produção orgânica, aponta para importantes relações atualmente presentes no processo de construção dos mercados. Os referenciais de qualidade, baseados na noção de segurança alimentar, se constituem em novos parâmetros de competitividade, dentro do atual contexto do agronegócio (SCHULTZ, 2006).

A noção de qualidade é definida por Wilkinson (1999) como um elemento fundamental para o entendimento da atual reestruturação agroalimentar e das diversidades de comportamento organizacional. Assim, a qualidade assume um papel explicativo central nas dinâmicas institucionais e competitivas das relações econômicas, principalmente com a grande ênfase atualmente atribuída aos processos de rotulagem e de normatização, onde estão inseridos os mais diversos tipos de produtos e produtores, desde os mais artesanais aos com maior aporte tecnológico padronizado.

A qualidade na agricultura orgânica está relacionada à noção de segurança alimentar. Spers (2000) identifica duas abordagens relacionadas a segurança e qualidade sob o enfoque alimentar. Primeiro diz respeito à segurança alimentar sob o enfoque quantitativo ou food security e está relacionado a renda do consumidor, a oferta interna disponível e às importações de alimentos. A segunda abordagem diz respeito à segurança do alimento sob o enfoque qualitativo ou food safety e está relacionado aos novos processos de industrialização e ao comportamento do consumidor com relação a sua saúde.

Paulillo \& Pessanha (2002:48) afirmam que "[...] a segurança alimentar se desenvolve ao redor de novos valores socialmente construídos e compartidos, como a nutrição, a saúde, a natureza, a autenticidade e a ecologia, além da funcionalidade e da adaptação de um padrão alimentar com eqüidade para a população mal nutrida.”

Sob esta perspectiva, a agricultura orgânica está inserida nas tendências atuais de sustentabilidade ambiental, de consumo consciente, de desenvolvimento territorial, de responsabilidade social, de segurança alimentar, de inclusão social, de agregação de valor para a agricultura familiar e de promoção da participação e da autogestão no meio 
rural.

São estes aspectos, de crescente valorização e institucionalização pela sociedade, que possibilitam o crescimento do mercado, interno e externo, para os produtos “orgânicos". Portanto, as fontes de valorização desses produtos podem estar associadas a forma de relação com o mercado, com as relações institucionais estabelecidas pelas organizações de agricultores, bem como pela forma de condução e gestão das atividades produtivas.

Mediante os processos de institucionalização, as crenças e cognições socialmente criadas tomam o caráter de algo que se dá por consolidado, e se convertem no atual modo natural de agir, sendo que os atores buscam transmitir o que socialmente se define como real (ZUCKER, 1999). V. Fonseca (2003:58) define institucionalização como "o processo de transformar crenças e ações em regras de conduta social".

Ao reproduzirem o discurso ambientalista, os agricultores reforçam a sua atividade como a de produtores envolvidos com a produção orgânica, promovendo destaque social para a sua condição, enquanto atores (organização) comprometidos com a sociedade e, ao mesmo tempo, contribuindo com a divulgação do consumo de alimentos saudáveis. Além dos aspectos ambientais, esses novos valores também incluem a solidariedade, os processos participativos e de resgate da cidadania, os mercados alternativos, a certificação e a rastreabilidade dos alimentos, que se fundamentam nos aspectos relacionados à higiene e à reeducação alimentar.

A estratégia de segurança alimentar, conforme Vieira (2004), é uma forma de garantir soberania alimentar, sendo que esta possui relação com a inserção dos agricultores no mercado de forma progressiva, ou seja, a partir da sua autosuficiência alimentar (autoconsumo), as relações destes agricultores com o mercado avançam para canais alternativos de comercialização, tais como as feiras. Portanto, a noção de segurança alimentar ${ }^{7}$ considera como fundamentais: o acesso aos mercados, por parte

\footnotetext{
${ }^{7}$ Conway ( 2003, p.322) cita estudo do Institute of Development Studies onde são identificados mais de 200 definições diferentes para segurança alimentar, oriundas da discussões políticas em fóruns internacionais e das percepções subjetivas sobre a noção de segurança alimentar: SMITH, POINTING, MAXWELL, 1992.
} 
dos produtores e consumidores; a garantia de atributos qualitativos, com ênfase na preservação ambiental e a educação alimentar, com resgate de hábitos alimentares da população.

As pressões socioculturais influenciam as organizações, sendo criados "mitos racionalizados", os quais serão utilizados como referências para a definição das estratégias destas organizações, em contraposição à predominância do poder determinante das demandas técnicas e de mercado, enquanto elementos condutores dos diferentes comportamentos organizacionais. (MEYER; ROWAN, 1999). Segundo Berger e Luckmann (1985:87), a “institucionalização ocorre sempre que há uma tipificação recíproca de ações habituais por tipos de atores."

As organizações de produção orgânica contribuem, ainda que de forma tímida, para o atendimento das necessidades crescentes de consumo relacionado a revalorização dos espaços públicos (feiras) e de princípios tais como, diálogo, amizade, confraternização e cooperação. A produção orgânica, oportuniza, portanto, a oferta de atributos que são valorizados pelos consumidores que extrapolam os simples aspectos relacionados aos produtos, tais como embalagem, marca, rótulo, textura ou sabor. Nesse sentido, a comercialização local (feiras livres) e por meio do agroturismo proporcionam o contato direto dos agricultores com o consumidor, sem que ele tenha que se deslocar de sua propriedade, proporcionando uma valorização adicional para a atividade desenvolvida, a partir de da integração da sua família com os visitantes e consumidores.

Meirelles (2004) define o mercado local não somente com relação à sua localização geográfica, mas como "um processo de comercialização", caracterizado, principalmente, pelo amplo acesso aos consumidores e aos produtores de alimentos ecológicos para os mercados. E este acesso passa a ser mais facilitado pelo maior vínculo, pelo estabelecimento de relações solidárias entre compradores e vendedores, baseado na cooperação, na transparência e na distribuição dos benefícios, e também pela valorização dos serviços sócio-ambientais gerados pela produção agroecológica.

A manutenção da qualidade orgânica e da credibilidade da atividade agrícola depende fundamentalmente da ética profissional, sendo esta baseada não somente em normas e certificações, mas fundamentalmente na confiança e na harmonia entre os 
agricultores e consumidores. Além disto, se utilizam dessa condição de integrante da organização com o objetivo de resistir na atividade agrícola, aumentar a dedicação à família e ao compromisso com a propriedade. Conforme afirmam Meyer e Rowan (1999:103), "quanto mais a estrutura de uma organização se origina de mitos institucionalizados, maior é a ostentação de confiança, satisfação e boa fé, tanto interna quanto externamente". Esses "mitos institucionalizados", oriundos da noção de qualidade e segurança alimentar na agricultura orgânica, estão relacionados à Agroecologia, sendo esta, como afirma Guzmán (1997:30), uma nova perspectiva de construção do conhecimento, baseada em uma "nova epistemologia, participativa e de caráter político".

O enfoque agroecológico, conforme Guzmán (1997), é baseado em uma relação entre o conhecimento científico e outras formas de conhecimento (locais, campesinos e indígenas), acumuladas historicamente, sobre os agroecossistemas, definindo-se como uma estratégia importante para a promoção da biodiversidade, tanto ecológica quanto sociocultural. Para o autor, a agroecologia consiste no "manejo ecológico dos recursos naturais que, incorporando uma ação social coletiva, de caráter participativo, permita projetar métodos de desenvolvimento sustentável" (GUZMÁN, 1997:29).

A diversidade, a autonomia e o respeito aos ciclos naturais de produção são os novos elementos oriundos da agroecologia que estão sendo transpostos para as lógicas de comercialização, o que traz inúmeros desafios para consolidação das atividades econômicas dos grupos de agricultores. Atualmente a definição dos produtos e das estratégias de mercado é um processo espontâneo no interior das organizações de agricultores. Sobre a existência de um "ponto de chegada" para os agricultores, que oriente os trabalhos dos grupos estudados, identifica-se a implantação de sistemas agroflorestais nas propriedades como eixo norteador principal. Nesse mesmo sentido, as sementes (crioulas) possuem um papel estratégico na promoção da agricultura "agroecológica" e possibilita a redução de custos na propriedade diminuindo a dependência externa, estimulando a biodiversidade e as relações entre os agricultores (sistema de trocas) na construção de conhecimentos locais sobre os sistemas de produção. 
Essas estratégias de utilização de valores associados à biodiversidade possibilita a diferenciação dos produtos nos mercados, afastando-se da produção realizada simplesmente sem produtos químicos e por empresas também inseridas na produção convencional. Algumas das organizações estudadas possuem a expectativa de oferta de "produtos crioulos", que além de orgânicos, despertam nos consumidores a conscientização por uma alimentação mais diversificada.

No contato direto com os consumidores buscam ressaltar as características específicas da agrofloresta e dos produtos ecológicos resultantes desse sistemas de produção, constituindo-se de uma possível estratégia de diferenciação e agregação de valor, em locais onde predomina a Mata Atlântica com grande biodiversidade de ecossistemas. Entretanto, já existe sinalização de consolidação dessa estratégia de valorização dos produtos orgânicos, com a formação de um grupo de trabalho sobre sistemas agroflorestais no âmbito da Rede Ecovida de Agroecologia. Esse grupo está propondo a criação de um selo "agroflorestal" com o objetivo de diferenciar os produtos no mercado, tanto de outros sistemas de agroflorestas existentes no Brasil, como de outros produtos orgânicos.

A partir das organizações de agricultores estudadas, identifica-se que o sentido das relações com o mercado na agricultura orgânica, no Sul do Brasil, está baseado em referências oriundas do processo de institucionalização em torno da construção social da noção de qualidade dos alimentos. Destacam-se, predominantemente nessa (re) construção dos mercados, os valores associados a biodiversidade (sustentabilidade) e ao acesso aos mercados (autenticidade), aspectos esses que vinculam-se à abordagem da segurança alimentar.

Novos elementos são inseridos na discussão sobre desenvolvimento rural, onde o "local" assume um papel de destaque nas políticas públicas. A agricultura orgânica contribui com esse processo, baseado na abordagem da segurança alimentar, privilegiando os mercados locais e a produção para o consumo da famílias de agricultores. A noção de segurança alimentar pressupõe o estabelecimento de uma nova relação entre o rural e o urbano, ampliando a oferta de alimentos de qualidade e a diversidade de hábitos de consumo (MALUF, 2002:241). 
As estratégias associadas à noção de segurança alimentar, por sua vez, necessitam de uma redefinição das políticas públicas e do papel do Estado (MALUF, 2002; SPERS, 2000; BELIK, 2003; ZYLBERSZTAJN, 2003; PESSANHA, 2002). Pessanha (2002) afirma que definir a segurança alimentar como “ [...] um princípio norteador de políticas públicas significa reconhecer suas múltiplas implicações e conexões, que se refletem nos diferentes campos de disputas e articulações que se constituem em torno das ações do Estado."

As dimensões que são inseridas para pensar o desenvolvimento são o "local" ou o "endógeno", onde os sistemas produtivos e a sua reestruturação estão baseados na identidade (como forma de agregação de valor e diferenciação), em redes de cooperação horizontal, em iniciativas próprias e na revitalização dos poderes locais. A busca de políticas que considerem o local como dimensão preponderante na definição de estratégias de desenvolvimento assumem atualmente um espaço privilegiado nos debates em diversas instâncias, sendo os mecanismos de governança, as formas indutoras da coordenação dos atores e o fortalecimento do capital social os aspectos centrais nessas análises. As organizações de agricultores que atuam com produção orgânica (re) valorizam esse debate em torno da promoção do desenvolvimento, identicando-se como determinantes nesse processo a institucionalização das relações com o mercado, a partir do enfoque científico baseado na agroecologia e na abordagem da segurança alimentar como norteadora das políticas públicas no Brasil. 


\section{REFERÊNCIAS}

ALMEIDA, J. P. de. Significados sociais, desafios e potencialidades da agroecologia. In: FERREIRA, A. D. D.; BRANDENBURG, A. Para pensar outra agricultura. Curitiba: Editora da UFPR, 1998. p. 239 - 247.

ALVES-MAZZOTTI, A. J.; GEWANDSZNAJDER, F. O método nas ciências naturais e sociais: pesquisa quantitativa e qualitativa. São Paulo: Pioneira Thompson Learning, 2004.

ASSIS, R. L. de. Agroecologia, agricultura orgânica e mercado. In: CONGRESSO BRASILEIRO DE ECONOMIA E SOCIOLOGIA RURAL, 40., 2002b, Passo Fundo. [Anais...] Brasília: SOBER, 2002. 1 CD-ROM.

ALTIERI, M. A. Agroecologia: as bases científicas da agricultura alternativa. Rio de Janeiro: PTA/FASE, 1989.

BELIK, W. Segurança alimentar: a contribuição das universidades. São Paulo: Instituto Ethos, 2003.

BERGER, P.; LUCKMANN, T. A construção social da realidade:tratado de sociologia do conhecimento. 6. ed. Petrópolis: Vozes, 1985.

BRASIL. Lei $\mathbf{n}^{\mathbf{0}} \mathbf{1 0 . 8 3 1}$, de 23 dezembro de 2003. Dispõe sobre a agricultura orgânica e dá outras providências. Disponível em: http://www.planetaorganico.com.br/lei23dez03.htm. Acesso em: 20 de janeiro de 2006.

CANUTO, J. C. Agricultura ecológica en Brasil: perspectivas socioecológicas. 1998. 256 f. Tesis (Doctor Ingeniero Agrónomo) - Programa Agroecología, Campesinado e Historia, Instituto de Sociología y Estudios Campesinos, Escuela Superior de Ingenieros Agrónomos y Montes, Universidad de Córdoba, Córdoba, $1998 . \quad$ Disponível em: http://www.pronaf.gov.br/dater/arquivos/0811810013.pdf. Acesso em $20 \mathrm{de}$ janeiro de 2006.

CAPORAL, F.; COSTABEBER, J. A. Agroecologia: enfoque científico e estratégico para apoiar o desenvolvimento rural sustentável. Porto Alegre: Emater/Ascar, 2002. (Série Programa de Formação Técnico Social da Emater/RS. Sustentabilidade e Cidadania, v. 5).

COMISSÃO MUNDIAL SOBRE MEIO AMBIENTE E DESENVOLVIMENTO. Nosso futuro comum. 2. ed. Rio de Janeiro: Fundação Getúlio Vargas, 1991.

CONWEY, G. Produção de Alimentos no século XXI: biotecnologia e meio ambiente. São Paulo: Estação Liberdade, 2003.

DAROLDT, M. R. Agricultura orgânica: inventando o futuro. Londrina: IAPAR, 2002. 
DULLEY, R. D. Ambiente e produção agrícola: principais paradigmas. 2003. 440 p. : il. Tese (Doutorado) - Universidade Estadual de Campinas . Instituto de Filosofia e Ciências Humanas, Campinas, 2003.

EHLERS, E. Agricultura sustentável: origens e perspectivas de um novo paradigma. São Paulo:Livros da terra, 1996.

FONSECA, V. S. da. A abordagem institucional nos estudos organizacionais: bases conceituais e desenvolvimentos contemporâneos. In: VIEIRA, M. M. F.; CARVALHO, C. A. (Org.) Organizações, instituições e poder no Brasil. Rio de Janeiro: FGV, 2003. p. 47-66.

FONSECA, M. F. de A. C. A institucionalização dos mercados de orgânicos no mundo e no Brasil: uma interpretação. 2005. 476 p. Tese (Doutorado) - Curso de Pós-Graduação em Desenvolvimento, Agricultura e Sociedade, Instituto de Ciências Sociais e Humanas, Universidade Federal Rural do Rio de Janeiro, Seropédica, 2005.

GUIVANT. J. S. Os supermercados na oferta de alimentos orgânicos: apelando ao estilo de vida ego-trip. Revista Ambiente \& Sociedade - Vol. VI, nº 2 julho/dezembro de 2003.

GUIVANT, J. S. et al. Os supermercados e o consumo de Frutas, Legumes, Verduras, (FLV) orgânicos certificados. 2003. Relatório final de pesquisa. Projeto CNPq $\quad \mathrm{n}^{\mathrm{o}}$ 520874/01-3. Disponível em: http://www.planetaorganico.com.br/trabflv.htm. Acesso em: 15 jan. 2006.

GUZMÁN, E. S. Origem, evolução e perspectivas do desenvolvimento sustentável. In: ALMEIDA, J.; NAVARRO, Z. (Org.). Reconstruindo a agricultura: idéias e ideais na perspectiva de um desenvolvimento rural sustentável. Porto Alegre: Editora da UFRGS, 1997. p. 19-31.

HECHT, S. B. A evolução do pensamento agroecológico. In: ALTIERI, M. A Agroecologia: as bases científicas da agricultura alternativa. Rio de Janeiro: PTA/FASE, 1989. p. 25-41.

LENOURD, A. P.; PIOVANO, M. Latin America: Country Reports. In: WILLER, H.; YUSSEFI, M. (Eds). The world of organic agriculture 2004: statistics and emerging trends. Bonn: International Federation of Organic Ag agriculture Movements, 2004. Disponível em: http://www.soel.de/oekolandbau/weltweit.html. Acesso em: 15 de out. 2005.

MACHADO-DA-SILVA, C. L.; FONSECA, V. S. da. Competitividade organizacional: conciliando padrões concorrenciais e padrões institucionais. In: VIEIRA, M. M. F.; OLIVEIRA, L. M. B. (Org.). Administração contemporânea: perspectivas estratégicas. São Paulo: Atlas, 1999. p. 27-39.

MALUF, R. S. Produtos agroalimentares, agricultura multifuncional e desenvolvimento territorial no Brasil. In: MOREIRA, R. J.; COSTA, L. F. de C. (Org.). Mundo rural e cultura. Rio de Janeiro: Mauad, [2002]. 
MEIRELLES, A. Cooperativa de Consumidores de Produtos Ecológicos: uma idéia que veio para ficar no Litoral do RS e Sul de SC. Revista Agroecologia Hoje, ano 4, n. 26, p. 06-07. ago./set. 2004.

MEYER, J. W.; ROWAN, B. Organizaciones institucionalizadas: la estructura formal como mito y cerimonia. In: POWELL, W. W.; DI MAGGIO, P. J. (Comp.). El nuevo institucionalismo en el análisis organizacional. México: Universidade Autónoma del Estado de México/Fondo de Cultura Económica, 1999. p. 79 103.

PAULILLO, L. F.; PESSANHA, L. D. R. Segurança alimentar e políticas públicas: conexões, implicações e regionalização. In: PAULILLO, L.; ALVES, F. (Org.). Reestruturação agroindustrial: políticas públicas e segurança alimentar regional. São Carlos: Editora da UFSCAR, 2002. p.17-55.

PAULUS, G. Do padrão moderno à agricultura alternativa: possibilidades de transição. 1999. 171 f. : il. Dissertação (Mestrado) - Programa de PósGraduação em Agroecossistemas, Centro de Ciências Agrárias, Universidade Federal de Santa Catarina, Florianópolis, 1999.

PESSANHA, L. D. R. O sentido brasileiro da segurança alimentar. In: MOREIRA, R. J.; COSTA, L. F. C. (Org.). Mundo rural e cultura. Rio de Janeiro: Mauad, 2002. p. 263-284.

SCHULTZ, G. Relações com o mercado e (re) construção das identidades socioprofissionais na agricultura orgânica. 2006. 280 p. Tese (Doutorado) Curso de Pós - Graduação em Agronegócios, Centro de Estudos e Pesquisas em Agronegócios, Universidade Federal do Rio Grande do Sul, Porto Alegre, 2006.

SCOTT, W. R.; MEYER, J. W. La organización de los sectores sociales: proposiciones y primeras evidencias. In: POWELL, W. W.; DI MAGGIO, P. J. (Comp.). El nuevo institucionalismo en el análisis organizacional. México: Universidade Autónoma del Estado de México/Fondo de Cultura Económica, 1999. p. 154190.

SMITH, M.; POINTING, J.; MAXWELL, S. Household Food Security, Concepts and Definitions: An Annotated Bibliography. Brighton: Institute of Development Studies, University os Sussex (Development Bibliography, n.8), 1992.

SPERS, E. E. Qualidade e segurança em alimentos. In: ZYLBERSZTAJN, D.; NEVES, M. F. (Org.). Economia e gestão dos negócios agroalimentares: indústria de alimentos, indústria de insumos, produção agropecuária e distribuição. São Paulo: Pioneira, 2000. p.283-321.

VIEIRA, M. M. F.; CARVALHO, C. A. Sobre organizações, instituições e poder. In: VIEIRA, M. M. F.; CARVALHO, C. A. (Org.) Organizações, instituições e poder no Brasil. Rio de Janeiro: Editora FGV, 2003. p. 11-26.

VIEIRA, G. Z. Feiras de Produtos Ecológicos: do anonimato ao protagonismo de agricultores e consumidores. Revista Agroecologia Hoje. Ano IV, $\mathrm{n}^{\mathbf{o}} 26$. Agosto/Setembro de 2004. 
VIEIRA, M. M. F.; ZOUAIN, D. M. (Org.). Pesquisa qualitativa em administração. Rio de Janeiro: Editora FGV, 2004.

WILKINSON, J. A contribuição da teoria francesa das convenções para os estudos agroalimentares: algumas considerações iniciais. Ensaios FEE, Porto Alegre, v. 20, n. 2, p. 64-80, 1999.

WILLER, H.; YUSSEFI, M. (Eds) The world of organic agriculture: statistics and emerging trends. 2006. Bonn: Germany: International Federation of Organic Agriculture Movements (IFOAM)/Research Institute of Organic Agriculture(FiBL - Frick, Switzerland)/Foudation Ecology \& Farming (SOEL), 2006. Disponível em: http://www.soel.de/oekolandbau/weltweit.html. Acesso em 28 jun. 2006

YIN, R. K. Estudo de Caso: planejamento e métodos. 3. ed. Porto Alegre: Bookman, 2005.

ZUCKER, L. G. El papel de la institucionalización en la persistencia cultural. In: POWELL, W. W.; DI MAGGIO, P. J. (Comp.). El nuevo institucionalismo en el análisis organizacional. México: Universidade Autónoma del Estado de México/Fondo de Cultura Económica, 1999. p. 126-153.

ZUCKER, L. G.; TOLBERT, P. S. A institucionalização da teoria institucional. In: CLEGG; S. R.; HARDY, C. NORD, W. R. (Org.); CALDAS, M.; FACHIN, R.; FISCHER, T. (Org. ed. brasileira). Handbook de estudos organizacionais: modelos de análise e novas questões em estudos organizacionais. São Paulo: Atlas, 1999. v. 1. p. 196-219.

ZYLBERSZTAJN, D. Revisando o papel do Estado. In: ZYLBERSZTAJN, D.; SCARE, R. F. (Org.). Gestão da qualidade no agribusiness: estudos e casos. São Paulo: Atlas, 2003. p. 80-91. 